\title{
A autoridade, o laço grupal e a construção de caminhos possíveis
}

Fernanda Ferreira Montes*

RESUMO: o artigo busca compreender, a partir da psicanálise e da psicossociologia francesa, a formação do laço social face à questão moderna da autoridade e do poder. O presente texto analisa o que sustenta a vida em sociedade, com o intuito de buscar caminhos possíveis para a manutenção da vida social pacífica.

PALAVRAS-CHAVE: psicanálise, grupo, autoridade, poder, criatividade.

\section{Authority, group bond and the construction of possible paths}

\begin{abstract}
This article seeks to understand the formation of the social bond in the face of the modern question of the authority and power, based on psychoanalysis and French psychosociology. The text analyzes what sustains life in society, aiming to find possible ways to maintain a peaceful social life.
\end{abstract}

KEYWORDS: psychoanalysis, group, authority, power, creativity

\section{L'autorité, les liens de groupe et la construction de chemins possibles}

RÉSUMÉ : L’article vise à comprendre, à partir de la psychanalyse et de la psychosociologie françaises, la formation des liens sociaux face à la question moderne de l'autorité et du pouvoir. Notre texte analyse ce qui maintient la vie en société afin de rechercher les moyens possibles de maintenir une vie sociale paisible.

MOTS CLÉS : psychanalyse, groupe, autorité, pouvoir, créativité.

* Doutora em Teoria Psicanalítica pelo Programa de Pós-Graduação em Teoria Psicanalítica da UFRJ, professora da Faculdade de Educação da UFF. E-mail: fernandamontes@id.uff.br 
Muito se produziu sobre a questão da autoridade na modernidade, apontando para seu declínio como algo intrínseco aos ideais individualistas modernos. Mas o fato é que não temos um consenso sobre o conceito de autoridade e sua diferenciação ou relação com o conceito de poder, por exemplo. Nesse trabalho não temos a pretensão ou ilusão de encontrar um fechamento resolutivo para tal problema, mas abrir questionamentos que nos possibilite uma produção teórica criativa em torno de temas tão caros ao nosso momento histórico.

Enquanto para Arendt (2009) - no artigo "Que é autoridade?"- a autoridade não pode ser confundida com força, coerção ou persuasão, em Enriquez (2007) - no texto “As figuras do poder" - o termo autoridade tem sido cada vez mais empregado no lugar do termo poder tendo em vista a carga emocional inerente ao último, que pode ser manifesto tanto através da força quanto da regra ou ainda pela dádiva.

Para Enriquez (2007), o poder surge nas instituições, traz consigo a questão da lei e suas modalidades de internalização são pelo amor, pela obrigação e pela educação. O poder se situa no nível político da regulação social, inconsciente na medida em que as instituições estão sempre ocultas, através do recalcamento e da internalização das normas, ou sob o manto das condutas sociais tendo em vista que as instituições que guiam nossas ações não são desveladas, sendo atravessadas pelo imaginário social.

O registro da autoridade, segundo Enriquez (2007), estaria localizado num nível organizacional, a fim de gerir a boa organização do coletivo. A autoridade teria graus de centralização ou descentralização, funcionando desde a modalidade de estrutura hierárquica pura até a assembleia geral. O autor observa que a concentração de trabalhos em torno da autoridade se relaciona com o fato das instituições estarem sempre ocultas. No entanto, considera que o foco nesse nível organizacional muitas vezes fez desaparecer a questão do poder. Citando Enriquez (2007, p.61): "Pesquisadores e profissionais tentaram descobrir de que maneira seria possível estruturar melhor a organização, descentralizar a autoridade, incentivar a participação, fingindo não mais haver problemas de poder". Assim, o autor ressalta que essa abordagem transformaria as relações de dominação em relações de autoridade, as relações sociais em humanas interpessoais ou intergrupais, os problemas de políticas e de objetivos em problemas de estrutura e de tecnologia. Portanto, colocar os problemas unicamente em termos de autoridade significaria lançar luz ao que é explicitamente consciente, sem fazer referência à cena inconsciente. 


\section{Autoridade, Poder e Laço Social}

Desta maneira, recorreremos ao texto freudiano sobre os laços sociais e a figura do líder a fim de compreender melhor a formação do laço social face à questão moderna da autoridade e do poder a fim de discorrer minimamente sobre os destinos da vida em sociedade, buscando caminhos possíveis para a manutenção da vida social pacífica.

A partir do texto "Psicologia de grupo e a análise do ego", Freud (1921/1996) nos apresenta a psicologia social como uma disciplina muito próxima à psicologia individual na medida em que é balizada pelos mesmos fundamentos conceituais tais como identificação, idealização, pulsões de vida e morte. Nesse viés, a formação dos grupos e do próprio laço social é diretamente relacionada ao amor ao semelhante, a fascinação ao líder e à constituição fraterna via identificação. No entanto, a questão do ódio é revelada a partir do encontro com o estrangeiro; com o estranho. Portanto, não somente o amor solidificaria um grupo, mas também o ódio ao diferente; ao "fora do grupo". Até o ódio ao líder poderia funcionar como unificador de laços grupais. Nesse contexto, a pulsão de morte se impõe como aquela que sempre se encontraria imbricada à pulsão de vida. Os destinos desse conflito pulsional, assim como os destinos dos grupos poderiam ser diversos, inclusive a violência e a tirania. Sendo assim, o que garantiria um caminho possível para a manutenção do laço social e a evitação da violência?

Em “Por que a Guerra?”, Freud (1932/1996) escreve:

A comunidade deve manter-se permanentemente, deve organizar-se, deve estabelecer regulamentos para antecipar-se ao risco de rebelião e deve instituir autoridades para fazer com que esses regulamentos — as leis — sejam respeitadas, e para superintender a execução dos atos legais de violência. O reconhecimento de uma entidade de interesses como estes levou ao surgimento de vínculos emocionais entre os membros de um grupo de pessoas unidas - sentimentos comuns, que são a verdadeira fonte de sua força (FREUD, 1932/1996, pag 199).

Portanto, Freud nos aponta que devemos instituir autoridades que garantam a lei a fim de controlar a violência. Em sua compreensão, não há maneira de eliminar totalmente os impulsos agressivos, mas podemos tentar desviá-los para que não precisem encontrar expressão na violência.

A figura da autoridade aparece como quem arbitra os conflitos de interesses. Afinal, para Freud, temos duas condições de possibilidade para que uma comunidade se mantenha unida: pela força coercitiva da violência e pelo laço indentificatório. 
Em "Psicologia de grupo e a análise do ego", Freud (1921/1996) trilhou o funcionamento dos mecanismos identificatórios para descrever o laço social. Identificações seriam laços emocionais que sustentam a vida social.

No texto de 1921, Freud nos permite pensar que a vida anímica de cada sujeito é inseparável da sua inserção na comunidade humana. O indivíduo é constituído pela sua relação com o outro e isso é um processo constante se entendemos o ego pelo seu caráter identificatório. Logo, a identificação opera como um modo fundamental e originário de ligação entre os sujeitos. Freud (1921/1996) afirma que a identificação é conhecida pela psicanálise como a mais remota expressão de um laço emocional com outra pessoa - porém, ambivalente desde o início - e desempenha um papel importante na história primitiva do Complexo de Édipo.

A partir da leitura desse texto, então, podemos pensar que o que mantém um grupo (em sentido mais amplo) é seu laço de caráter erótico. O que estaria em jogo seria o amor e a libido. Os processos primitivos de identificação para a constituição do próprio sujeito são abordados a fim de explicar as formações sociais.

Nesse sentido haveria uma dupla ligação libidinal no grupo: entre os membros do grupo e dos membros com o líder. Encontramos aqui a identificação entre pares e a identificação com o líder. Seriam processos identificatórios distintos. A identificação com o líder seria do tipo narcísica e o líder ocuparia o lugar de ideal do ego. Freud encontra uma ilustração interessante para esse funcionamento identificatório em dois grandes grupos artificiais: o exército e a igreja. Ambos teriam líderes que amam a todos os membros dos grupos na mesma medida ignorando as individualidades, tratando-os como massa. A relação com o líder seria hipnótica. Inclusive, temos a afirmação de que o pânico se instalaria com a perda do líder, quando os laços libidinais tenderiam a se desintegrar.

\section{Identificação e Idealização: entre o amor e a fascinação}

Ao observar as sociedades, percebemos que o amor atua mesmo como fator civilizador. Mas obedece aos limites do narcisismo. Aqui precisamos compreender que Freud faz a distinção entre a identificação do ego com um objeto, que é a identificação entre os membros do coletivo, e a substituição do ideal do ego por um objeto, a idealização, mecanismo comum em relação ao líder.

Na idealização, o objeto é tratado da mesma maneira que o ego. A libido transborda para o objeto. O objeto torna-se sucedâneo para algo inatingido pelo ideal do ego. O objeto toma lugar no ego. Se na identificação há o enriquecimento ego, que recolhe traços do objeto, na idealização percebemos o 
empobrecimento do ego na medida em que ele se entrega ao objeto. O objeto idealizado substitui um importante constituinte do ego. Nesse caso teríamos a fascinação e nenhuma possibilidade de acréscimo ao ego tal como na identificação ou na relação amorosa partilhada.

Sobre a fascinação ou servidão, Freud aponta que o hipnotizador, assim como o líder, também ocupa o lugar do ideal do ego. Ele nos chama atenção para a posição do indivíduo em relação ao líder como ocorre na hipnose. E aqui ressaltamos as observações de Ferenczi (1909/1992) sobre a hipnose materna e paterna em seu trabalho intitulado "Transferência e Introjeção". Conforme Ferenczi (1909/1992), a condição de êxito da hipnose é que o hipnotizador saiba despertar no indivíduo os mesmos afetos de amor ou temor e a mesma fé cega que a criança sentia por seus pais. Ferenczi compreende que a situação de hipnose evoca a infância, a época da obediência infantil (que tem sua cota de prazer). Ferenczi nos indica que é importante marcar que o hipnotizador seria uma pessoa que intercalaria uma imagem de onipotência e certo tom de intimidação com um acolhimento tranqüilizador. Os adultos que ocupam essas funções teriam uma relação hipnótica com a criança e, assim, a palavra deles seria da ordem de uma verdade absoluta.

À vista disso, Ferenczi se remete a Freud no que diz respeito ao caráter infantil do inconsciente e às manifestações do funcionamento infantil do nosso psiquismo através dos sonhos, lapsos, atos falhos e chistes. "Raspem o adulto e por baixo dele encontrarão a criança" (FERENCZI, 1909, p.98).

Portanto, podemos concluir que a relação dos indivíduos de um grupo com o líder traz à tona a fé cega infantil, preservada inconscientemente. No entanto, segundo Ferenczi (1933/1992), a lógica da relação entre adultos estaria absolutamente balizada pela diferença sexual, pelo recalque e inserida numa ordem diferente da linguagem da ternura, que seria a única possível para a criança. Logo, a leitura que o indivíduo adulto faz do líder estaria no registro ferencziano da linguagem da paixão (FERENCZI, 1933/1992), na ordem de pathos como excesso, catástrofe ou assujeitamento. Desta forma, a relação com o líder seria análoga à fé cega infantil, mas num registro de pathos, evidenciando um amor - fascinação de servidão.

No texto “As figuras do poder”, Enriquez (2007) afirma que o amor e suas implicações narcísicas estariam sempre vinculados à ideia de poder em seus dois aspectos: o assimilável a Eros; às pulsões de vida; à ligação e o aspecto que remete ao fascínio; à perda de identidade; à vertigem, ao que nos remete à pulsão de morte. Se considerarmos as relações sustentadas pelo fascínio e pela idealização, o poder em questão não estaria regulado pela pulsão de vida, mas lançaria mão de uma máscara de amor para que a morte triunfe. No entanto, se o mecanismo de identificação ocupar a cena, será possível admitirmos um poder feito não apenas de repressão, mas de "instituição de formas vivas" (ENRIQUEZ, 2007, p.60). Citando Enriquez (2007, p.60): "Estamos realmente tratando da dupla face do narcisismo: da que 
representa a morte, a aniquilação na imagem especular em que o ser se perde, e da que possibilita a emergência do desejo, no júbilo do sentimento da existência, e que é a condição do amor".

Sobre questionamentos referentes ao poder e à lei, Freud (1932/1996), em "Por que a guerra?", ressalta que o líder se coloca como autoridade para suprir a imagem de um pai. No entanto, essa forma de laço é criticada por Freud, pela questão hierárquica estrutural. O abuso da autoridade se originaria da própria necessidade de um líder, dessa desigualdade estrutural, que divide a sociedade entre líderes e submissos. Os indivíduos teriam a tendência à essa divisão entre líderes e seguidores, sendo que os últimos seriam maioria e necessitariam de uma autoridade que tome decisões por eles. Afinal, a maioria dos indivíduos devotaria submissão ilimitada à autoridade.

De acordo com Freud (1932/1996), numa situação hipoteticamente ideal, o domínio da razão teria condições de unir os sujeitos ainda que não houvesse vínculos emocionais entre eles. Portanto, Freud (1932/1996) enxerga no uso da razão uma saída possível para esse impasse, mas reconhece o tom utópico desse argumento. Em linhas gerais, ele propõe um deslocamento para o intelecto e sublinha que o estreitamento dos laços emocionais de Eros e as identificações atuariam contra a violência. Conclui que tudo o que estimula o crescimento da civilização trabalharia simultaneamente contra a guerra, especialmente o fortalecimento da vida intelectual e a renúncia às pulsões. Nesse sentido Freud (1932/1996) afirma que um posicionamento contra a liberdade de pensamento não seria nada favorável à formação civilizatória.

Abordando a complexa relação entre sujeito e sociedade, em "O papel do sujeito humano na dinâmica social”, Enriquez (2001) trata da questão da heteronomia lançada por Kant - ou seja, da sujeição do indivíduo ao coletivo. Enriquez (2001) discute o quanto indivíduo e social se atravessam, podendo produzir indivíduos mais ou menos heterônimos ou autônomos. O autor relaciona a heteronomia à "doença do ideal".

A idealização desempenharia um papel fundamental na edificação de uma sociedade, mas também na produção de indivíduos heterônimos por aparentar garantir certa estabilidade psíquica na medida em que transmite uma mensagem de serenidade sobre uma suposta ordem social. Diz Enriquez (2001, p.32): "Se adoramos chefes que encarnam ideais fortes ou sociedades aparelhadas de virtudes admiráveis, nós próprios nos tornamos admiráveis. Miramo-nos no espelho que nos é estendido pelo próprio objeto de nossa admiração". Conforme o autor, a idealização permite a manutenção de toda a sociedade visto que o indivíduo pode aceitar o recalque e aderir às injunções sociais, muitas vezes trocando sua liberdade pela segurança da manutenção narcísica individual, apoiado pelo narcisismo grupal. O que Enriquez (2001, p.41) denomina "doença do ideal" seria a idealização que constrói identidades coletivas fortes, desprovidas de possibilidade de sublimação ou de possibilidade criativa, carregando não raramente ideais 
vazios e desprovidos de sentido como os ideais do consumo, por exemplo. E a tentativa de construção de identidades coletivas fortes favoreceria o narcisismo das pequenas diferenças (FREUD, 1818, 1921, 1930), conceito freudiano que visa esclarecer a ligação entre o coletivo por vínculos do amor entre os semelhantes e ataques ao estranho, através da satisfação da pulsão agressiva. Para Enriquez (2001, p.33), esse "narcisismo grupal" traz embutido o risco do racismo exacerbado, do fanatismo religioso e político, podendo atingir indivíduos de uma mesma cultura. Pois quanto mais uma cultura busca essa unificação, mais intolerante ela se torna, desejando a morte dos diferentes ou a sua conversão justamente por ser balizada pelo ódio numa espécie de uma alucinação coletiva, onde os estrangeiros seriam perseguidores onipotentes. Quanto mais a sociedade constrói uma identidade coletiva forte, menos temos indivíduos autônomos.

\section{Para concluir: construindo caminhos criativos}

Seguindo a proposta de Enriquez, o inverso do indivíduo agarrado aos ideais coletivos fortes seria justamente a figura do sujeito desejante, que aceita cotidianamente lidar com as impossibilidades mundanas e humanas de maneira criativa tal como Winnicott compreende a criatividade.

Nesse contexto, buscaremos na noção de criatividade Winnicottiana um outro destino possível para o laço grupal, que não a violência com raízes arcaicas na pulsão de morte.

Winnicott (1975) defende que a saúde depende de uma vida criativa. Sem criatividade, não há autenticidade. A saúde está na capacidade de ação do indivíduo, isto é, depende de um agir autêntico. O relaxamento em condições de confiança, a atividade criativa e a somação dessas experiências formam a base do self.

Neste ponto, sublinhamos a importância do conceito de transicionalidade em Winnicott (1975). Haveria um espaço de transição para que o bebê possa confiar no meio e alcançar o estado de relaxamento e não-integração fundamental para o agir autêntico sem o auxílio egóico materno. Afinal, uma diferença entre eu e não-eu precisa ser agenciada para que a distinção interno/externo se constitua. Desta maneira, a criação do espaço transicional - um espaço entre o mundo externo e o interno - seria fundamental nesse processo, possibilitando o agir criativo, exemplificado pelo brincar e pela associação livre. A criatividade, o brincar e a associação livre são da ordem da ação, completamente diferente da reação defensiva. A reação defensiva apenas tem lugar quando o meio é por demais falho ou intrusivo.

A criatividade pode ser concebida como "ícone" da ação por ter suas raízes nas primeiras relações do bebê com a mãe. Por isso, Winnicott (1951/2000) utiliza a noção de criatividade primária. Ela seria possibilitada pela experiência da ilusão, que permitiria que o bebê acreditasse que existe uma realidade 
externa de acordo com sua capacidade de criar, fornecida por um meio suficientemente bom. $\mathrm{Na}$ experiência da ilusão (WINNICOT'T, 1951/2000.), o bebê acreditaria que criou o seio, oferecido pela mãe no momento de sua necessidade. Essa mãe estaria no estado de preocupação materna primária, isto é, completamente identificada com o bebê. Essa experiência de ilusão aconteceria diversas vezes até o bebê poder ser desiludido. Os fenômenos transicionais ocupariam uma área intermediária entre a criatividade primária e o teste de realidade. Eles representariam um primeiro tipo de uso da ilusão (WINNICOTT, 1951/2000.).

O meio ambiente e a mãe suficientemente boa teriam, portanto, papéis fundamentais para Winnicott. Afinal, seria com a construção do espaço transicional que se poderia ter a noção de identidade e continuidade no tempo através da capacidade para agir no mundo de forma criativa. Primeiramente, este espaço seria construído entre a mãe, representante do ambiente, e o bebê. Neste espaço se instituiria o agir criativo, o gesto espontâneo e se consolidaria o verdadeiro self.

Se pensarmos na construção coletiva e na manutenção dos laços grupais através dos conceitos de criatividade e transicionalidade, talvez possamos prescindir da necessidade de uma autoridade sedutora, calcada na cena inconsciente relacionada às origens do poder do pai. O espaço transicional grupal, se assim pudermos conceber, nos levaria a ancorar a manutenção da fraternidade entre os indivíduos do coletivo numa persistente insistência na criatividade através do poder do amor de Eros, partilhado, das identificações constituídas a partir da abertura para o mundo e não da posição infantil de fascinação, sideração ou hipnose frente a autoridade dos pais. No entanto, esse processo de construção coletivo criativo dependeria de uma disposição narcísica de cada um para abrir mão das identidades fortes e suportar os estados de não-integração egóicos como fazem as crianças em suas brincadeiras e como fazem os artistas ao se colocarem em outras cenas.

Talvez essa seja uma proposta utópica e até ingênua por pretender a construção de outras cenas no social, a partir de uma face do narcisismo em detrimento da agressividade. De todo modo, vale o esforço em tentar pensar alternativas à violência que muito parece inerente à condição social. 


\section{REFERÊNCIAS}

ARENDT,H. Que é autoridade?, in Entre o passado e o futuro. SP: Perspectiva, 2009.

ENRIQUEZ, E. As figuras do poder. São Paulo, Via Lettera, 2007

O papel do sujeito humano na dinâmica social, in MACHADO \& ARAÚJO (org) Psicossociologia: análise social e intervenção. Belo Horizonte: Autêntica, 2001.

FERENCZI, S. (1909) “Transferência e introjeção”, in Psicanálise I. São Paulo: Martins Fontes, 1992. . (1933) Confusão de língua entre os adultos e a criança. Psicanálise IV, São Paulo: Martins Fontes, 1992.

FREUD, Sigmund. - O tabu da virgindade (1918), in: Edição Standard Brasileira das Obras Psicológicas Completas, Vol XI, Imago Editora, Rio de Janeiro, 1996.

. Psicologia de grupo e a análise do ego (1921), in: Edição Standard Brasileira das Obras Psicológicas Completas, Vol XVIII, Imago Editora, Rio de Janeiro, 1996.

. O mal-estar na civilização (1930), in: Edição Standard Brasileira das Obras Psicológicas Completas, Vol XXI, Imago Editora, Rio de Janeiro, 1996.

. Por que a guerra? (1933), in: Edição Standard Brasileira das Obras Psicológicas Completas, Vol XXII, Imago Editora, Rio de Janeiro, 1996.

WINNICOTTT, D. (1951) Objetos transicionais e fenômenos transicionais, in: Da Pediatria à Psicanálise: obras escolbidas. Rio de Janeiro, Imago, 2000 . (1975) O brincar e a realidade. Rio de Janeiro, Imago.

Recebido em: 10 de novembro de 2019.

Aprovado em: 5 de dezembro de 2019. 